DOI: 10.12731/2227-930X-2021-11-1-7-16 УДК 338.47

\title{
КОНКУРЕНТОСПОСОБНОСТЬ ТРАНСПОРТНЫХ КОРИДОРОВ РОССИИ В СИСТЕМЕ МЕЖДУНАРОДНЫХ ТРАНСПОРТНЫХ КОРИДОРОВ
}

\author{
Рочева О.А., Зарипова Р.С., \\ Морозова И.Г., Хамидуллина Ф.Р.
}

Общая экономическая ситуация в государстве также важна для развития СМП. Прежде всего, необходимо отметить негативное влияние снижения объемов производства. Значительная часть производственных мощңностей была закрыта. Общий объем грузопотока по Северному морскому пути сократился в четыре раза.

Арктические порты - слабое звено Северного морского пути, не отвечающее современным требованиям. Эти объекты были передань в доверительное управление рядом владельцев, которые в настоящее время не в состоянии обеспечить нормальную работу этих объектов.

Цель работы: изучить общую экономическую ситуацию в государстве также важна для развития СМП. Изучить объем грузопотока по Северному морскому пути.

Методология проведения работы: системный подход и обобщение; собственный научно-педагогический опыт авторов; аналитические и статистические методы анализа.

Результаты: Северньй морской путь характеризуется повышенным значением для современной России. Интерес всего мира к Северному морскому пути связан с тем, что он выступает важнейшим транспортным маршрутом, обеспечивающим освоение ресурсов Арктического региона, в том числе топливно-энергетических, осуществляющим высокодоходные транзитные перевоз$\kappa и$ и $\partial p$. 
Область применения результатов: полученные результаты иелесообразно применять на государственном уровне должно быть осознание того, что одной из ключевых задач нашей страны на современном этапе является развитие судоходства в Северном Ледовитом океане.

Ключевые слова: транспортный коридор; Арктика; грузоперевозки

\title{
COMPETITIVENESS OF RUSSIAN TRANSPORT CORRIDORS IN THE SYSTEM OF INTERNATIONAL TRANSPORT CORRIDORS
}

\author{
Rocheva O.A., Zaripova R.S., \\ Morozova I.G., Khamidullina F.R.
}

The overall economic situation in the state is also important for the development of the NSR. First of all, it is necessary to note the negative impact of the decline in production volumes. A significant part of the production facilities were closed. The total volume of cargo traffic along the Northern Sea Route has decreased by four times.

Arctic ports are a weak link of the Northern Sea Route that does not meet modern requirements. These properties have been placed in trust by a number of owners who are currently unable to ensure the normal operation of these properties.

The purpose of the work: to study the general economic situation in the state is also important for the development of the NSR. To study the volume of cargo traffic along the Northern Sea Route.

The methodology of the work: a systematic approach and generalization; the authors 'own scientific and pedagogical experience; analytical and statistical methods of analysis.

Results: The Northern Sea Route is characterized by an increased importance for modern Russia. The interest of the whole world in the Northern Sea Route is connected with the fact that it is the most important transport route that ensures the development of the resources 
of the Arctic region, including fuel and energy, carrying out high-yield transit transportation, etc.

Scope of application of the results: it is advisable to apply the results obtained at the state level, there should be an awareness that one of the key tasks of our country at the present stage is the development of navigation in the Arctic Ocean.

Keywords: transport corridor; Arctic; cargo transportation

\section{Введение}

Основная проблема СМП - инфраструктурная неразвитость российской Арктики, в том числе и самого транспортного коридора. Российская государственная программа «Социально-экономическое развитие Арктической зоны РФ» предполагает:

1. строительство и реконструкцию морских портов в Архангельске, Диксоне и Сабетте,

2. строительство двух железнодорожных веток от побережья Северного Ледовитого океана вглубь страны для взаимоувязки морской и железнодорожной инфраструктур,

3. разработку месторождений природных ресурсов на российском арктическом шельфе,

4. проведение мониторинга состояния окружающей среды,

5. развитие арктических технологий.

Цель работы: изучить общую экономическую ситуацию в государстве также важна для развития СМП. Изучить объем грузопотока по Северному морскому пути.

Методология проведения работы: системный подход и обобщение; собственный научно-педагогический опыт авторов; аналитические и статистические методы анализа.

\section{Результаты}

Главная проблема-неразвитость инфраструктуры российской Арктики, в том числе и самого транспортного коридора. Государственная программа РФ «Социально-экономическое развитие Арктической зоны Российской Федерации» предусматривает строи- 
тельство и реконструкцию морских портов Архангельск, Диксон и Сабетта, строительство двух железнодорожных линий от побережья Северного Ледовитого океана до внутренних районов страны для соединения морской и железнодорожной инфраструктуры, освоение природных ресурсов на российском арктическом шельфе, экологический мониторинг, развитие арктических технологий.

В 2018-2025 годах на реализацию программы планируется выделить около 3 миллиардов долларов. Однако на сегодняшний день запланированные строительные работы ведутся только в порту Сабетта, и по большинству заявленных проектов Россия рассчитывает привлечь средства из внебюджетных источников, в том числе рассчитывая на китайские инвестиции.

Общая экономическая ситуация в государстве также важна для развития СМП. Прежде всего, необходимо отметить негативное влияние снижения объемов производства. Значительная часть производственных предприятий была закрыта. Общий объем грузопотока по Северному морскому пути сократился в четыре раза.

Арктические порты - слабое звено Северного морского пути, не отвечающее современным требованиям. Эти объекты были переданы в доверительное управление ряду собственников, которые в настоящее время не в состоянии обеспечить нормальное функционирование этих объектов.

Нехватка средств, отсутствие целевого финансирования со стороны государства приводит к тому, что порты приходят в такое состояние, которое мешает их нормальному функционированию. Модернизация портовых механизмов и технического оснащения практически отсутствует. После распада СССР процессы разработки и внедрения новых технико-технологических элементов портового хозяйства практически прекратились.

В перспективе Китаю также необходимо создать собственный ледокольный флот, способный осуществлять навигацию не только по Северному морскому пути, но и по Трансполярному проходу. Однако при этом необходимо обеспечить максимальную загрузку маршрута, осуществляемую судами в период навигации, так как 
судоходный сезон на Северном морском пути длится всего четыре месяца, а остальное время ледокольный флот будет простаивать.

Среди технических рисков для иностранных судов на Северном морском пути основным является непредсказуемость ледовой обстановки, которая представляет угрозу для отдельных типов судов. По этой причине круизные суда могут быть вынуждены менять маршруты, что негативно скажется на спросе и популярности таких круизов среди потребителей.

В связи с этой ситуацией очевидна необходимость антимонопольных мер на национальном уровне.

Иностранные транспортные структуры также в настоящее время проявляют интерес к транзиту и транспортировке топлива на Севере. Однако это направление не получает должного развития из-за несовершенства нормативной базы, регулирующей данный процесс, и недостаточной государственной поддержки эксплуатации автомобильной дороги.

Кроме того, важным препятствием для расширения сотрудничества с зарубежными транспортными структурами является несоответствие отечественных норм нормам международного морского права и низкий уровень безопасности судоходства, характерный для нашей страны.

На государственном уровне должно быть осознание того, что одной из ключевых задач нашей страны на современном этапе является развитие судоходства в Северном Ледовитом океане. Высокая роль Северного морского пути обусловлена необходимостью транспортировки добываемых топливно - энергетических ресурсов и минерального сырья, добываемого на этих территориях.

Таким образом, Северный морской путь характеризуется повышенным значением для современной России. Интерес всего мира к Северному морскому пути связан с тем, что он выступает важнейшим транспортным маршрутом, обеспечивающим освоение ресурсов Арктического региона, в том числе топливно-энергетических, осуществляющим высокодоходные транзитные перевозки и др. 
В рамках этого видения Россия является одним из важнейших партнеров в Арктике, особенно учитывая, что Россия контролировала почти половину всего побережья Северного Ледовитого океана, а также земли и ресурсы вдоль Северного морского пути. Россия в целом поддерживает «Пояс и путь» и рассчитывает на включение Китая и других стран в инвестиционные проекты в Арктике и развитие транспортной инфраструктуры на Северном морском пути. Однако на пути к успешной реализации инициативы «Арктический голубой экономический коридор» существует ряд объективных проблем (ограниченность финансовых ресурсов, доступ к определенным технологиям из-за санкций, структурные проблемы российской экономики и др.), решение которых видится только при условии взаимных шагов России, Китая и других стран Юго-Восточной Азии.

\section{Сиисок литературы}

1. Зарипова Р.С., Рочева О.А. Разработка системы учета кадров для дорожного предприятия // Наука Красноярья. 2020. Т. 9, № 4-4. С. 108-112.

2. Рочева О.А., Зарипова Р.С., Морозова И.Г. Современное развитие Северного морского пути и его значимость для экономики России // Наука Красноярья. 2020. Т. 9, № 4-4. С. 208-214.

3. Чарикова И.Н., Жаданов В.И., Чарикова В.В., Попов И.А. Методологические аспекты преподавания спецкурса «Проектирование строительных объектов в арктических условиях» // Современные проблемы науки и образования. 2018. № 4. https://science-education. $\mathrm{ru} / \mathrm{ru} /$ article/view? $\mathrm{id}=27801$

4. Шакиров А.А., Зарипова Р.С. Особенности моделирования логистических систем // International Journal of Advanced Studies. 2019. T. 9, №4. C. 27-31.

5. Nengye Liu. China's Emerging Arctic Policy. China has a clear (though as yet unwritten) strategy for the Arctic. https://thediplomat. com/2016/12/chinas-emerging-arctic-policy/

6. Rocheva O., Khadiullina L., Zaripova R., Hamatgaleeva G., Kosulin V. The Arctic of the future: retrospective and perspective of research and 
development // Proceedings of the "New Silk Road: Business Cooperation and Prospective of Economic Development” (NSRBCPED 2019). Advances in Economics, Business and Management Research, 2019. Vol. 131. P. 640-644. https://dx.doi.org/10.2991/aebmr.k.200324.119

7. Tyurina M., Porunov A., Zaripova R., Gaynetdinova A., Kosulin V. Information and Measuring System for Ensuring and Monitoring Environmental Safety // Proceedings of the "New Silk Road: Business Cooperation and Prospective of Economic Development" (NSRBCPED 2019). Advances in Economics, Business and Management Research, 2019. Vol. 131. P. 648-653. https://dx.doi.org/10.2991/aebmr.k.200324.121

8. Zaripova R., Tyurina M., Rocheva O., Chupaev A., Sharifullina A. Major Trends in the Digital Transformation of Agriculture // Proceedings of the "New Silk Road: Business Cooperation and Prospective of Economic Development" (NSRBCPED 2019). Advances in Economics, Business and Management Research, 2019. Vol. 131. P. 271-275. https://dx.doi.org/10.2991/aebmr.k.200324.050

\section{References}

1. Zaripova R.S., Rocheva O.A. Razrabotka sistemy ucheta kadrov dlya dorozhnogo predpriyatiya [Development of a personnel accounting system for a road enterprise]. Nauka Krasnoyar'ya, 2020, vol. 9, no. 4-4, pp. 108-112.

2. Rocheva O.A., Zaripova R.S., Morozova I.G. Sovremennoe razvitie Severnogo morskogo puti i ego znachimost' dlya ekonomiki Rossii [Modern development of the Northern Sea Route and its significance for the Russian economy]. Nauka Krasnoyar'ya, 2020, vol. 9, no. 4-4, pp. 208-214.

3. Charikova I.N., Zhadanov V.I., Charikova V.V., Popov I.A. Metodologicheskie aspekty prepodavaniya spetskursa «Proektirovanie stroitel'nykh ob"ektov v arkticheskikh usloviyakh» [Methodological aspects of teaching the special course "Design of construction objects in the Arctic conditions"]. Sovremennye problemy nauki i obrazovaniya [Modern problems of science and education], 2018, no. 4. https://science-education.ru/ru/article/view? $\mathrm{id}=27801$ 
4. Shakirov A.A., Zaripova R.S. Osobennosti modelirovaniya logisticheskikh sistem [Features of modeling logistics systems]. International Journal of Advanced Studies, 2019, vol. 9, no. 4, pp. 27-31.

5. Nengye Liu. China's Emerging Arctic Policy. China has a clear (though as yet unwritten) strategy for the Arctic. https://thediplomat. com/2016/12/chinas-emerging-arctic-policy/

6. Rocheva O., Khadiullina L., Zaripova R., Hamatgaleeva G., Kosulin $\mathrm{V}$. The Arctic of the future: retrospective and perspective of research and development // Proceedings of the "New Silk Road: Business Cooperation and Prospective of Economic Development" (NSRBCPED 2019). Advances in Economics, Business and Management Research, 2019. Vol. 131. P. 640-644. https://dx.doi.org/10.2991/aebmr.k.200324.119

7. Tyurina M., Porunov A., Zaripova R., Gaynetdinova A., Kosulin V. Information and Measuring System for Ensuring and Monitoring Environmental Safety // Proceedings of the "New Silk Road: Business Cooperation and Prospective of Economic Development" (NSRBCPED 2019). Advances in Economics, Business and Management Research, 2019. Vol. 131. P. 648-653. https://dx.doi.org/10.2991/aebmr.k.200324.121

8. Zaripova R., Tyurina M., Rocheva O., Chupaev A., Sharifullina A. Major Trends in the Digital Transformation of Agriculture // Proceedings of the "New Silk Road: Business Cooperation and Prospective of Economic Development" (NSRBCPED 2019). Advances in Economics, Business and Management Research, 2019. Vol. 131. P. 271-275. https://dx.doi.org/10.2991/aebmr.k.200324.050

\section{ДАННЫЕ ОБ АВТОРАХ}

Рочева Ольга Александровна, ст. преподаватель кафедры «Менеджмента»

Казанский инновационный университет им. В.Г. Тимирясова ул. Московская, 42, г. Казань, Респ. Татарстан, 420111, Российская Федеращия rochevaolga@mail.ru 
Зарипова Римма Солтановна, доцент, кандидат технических наук

Казанский государственный энергетический университет ул. Красносельская, 51, г. Казань, Татарстан, 420066, Российская Федераиия zarim@rambler.ru

Морозова Ирина Геннадиевна, доцент кафедры «Менеджмента», кандидат экономических наук Казанский инноваиионный университет им. В.Г. Тимирясова ул. Московская, 42, г. Казань, Татарстан, 420111, Российская Федерачия igmorozova@ieml.ru

Хамидуллина Фания Рафиковна доцент кафедры «Менеджмента», кандидат экономических наук Казанский инновачионный университет им. В.Г. Тимирясова ул. Московская, 42, г. Казань, Татарстан, 420111, Российская Федерация hfr2005@mail.ru

\section{DATA ABOUT THE AUTHORS}

Olga A. Rocheva, Senior Lecturer of the Department of Management Kazan Innovative University named after V. G. Timiryasov 42, Moskovskaya Str., Kazan, Tatarstan, 420111, Russian Federation rochevaolga@mail.ru

Rimma S. Zaripova, Associate Professor, Candidate of Technical Sciences

Kazan State Power Engineering University

51, Krasnoselskaya Str., Kazan, Tatarstan, 420066, Russian Federation zarim@rambler.ru 
Irina G. Morozova, Associate Professor «Marketing and Economics», Candidate of Economic Sciences

Kazan Innovative University named after $V$. G. Timiryasov 42, Moskovskaya Str., Kazan, Tatarstan, 420111, Russian Federation igmorozova@ieml.ru

Fania R. Khamidullina, Associate Professor of the Department of "Management", Candidate of Economic Sciences Kazan Innovative University named after $V$. G. Timiryasov 42, Moskovskaya Str., Kazan, Tatarstan, 420111, Russian Federation hfr2005@mail.ru 